\title{
INTERNET, CIVIL SOCIETY AND GLOBAL GOVERNANCE: THE NEGLECTED POLITICAL DIMENSION OF THE DIGITAL DIVIDE
}

\author{
Dieter ZINNBAUER
}

\section{The Digital Divide}

The catchphrase of the "digital divide" has evolved into a central point of reference for policymakers and IT practitioners alike. It provides an imaginative shorthand for the multiple imbalances that characterize the diffusion of novel information and communication technologies (ICTs) along income, gender, age and many other socioeconomic categories. The numbers are well-known and widely published:

- At the beginning of 2000 USA, Europe and Japan account for more than $96 \%$ of Internet hosts in the world and their combined share has even slightly risen since $1998{ }^{1}$

- The already tiny share of Internet hosts in Sub-Sahara Africa has sharply fallen between 1998 and 2000 to $0.25 \%$ of total Internet hosts, while the growth in real terms has more or less stagnated; ${ }^{2}$

- $80 \%$ of Internet hosts are located in countries that speak English as their first language ${ }^{3}$

- The total of international Internet bandwidth for Africa, the aggregate size of the "data pipes" to other countries is less than that of Ankara; ${ }^{4}$

- In 1998, 94 out of the 100 most visited websites were located in the US. ${ }^{5}$

Without any doubt, these numbers are disconcerting but not unexpected. They closely mirror a myriad of other global disparities with regard to income, consumption of natural resources, ownership of patents, etc. ${ }^{6}$ Taken as stand-alone figures, these numerical snapshots of the digital divide can be even misleading. They tend to evoke strong reactions of two sorts: 
- The skeptical variant, which denies the immediate importance of these ICT inequities with a strong "important are teachers and vaccines, not computers" type of response; ${ }^{7}$ and,

- The "actionist" variant, which advocates the mobilization of resources on a massive scale and the establishment of a conducive regulatory economic environment to narrow the gap in ICT ownership and skills. ${ }^{8}$

These admittedly very stylized antipodes nurture each other and frame a very passionate but somewhat detached debate of the digital divide. However, in their myopic focus on the ICT resource gap they both highlight the need to move beyond the mapping of digital inequities and scrutinize both the transformational dynamics triggered and opportunities afforded by novel ICT in concrete applications and with regard to overarching goals of human development. This article speculates on the impact of the global digital divide with regard to participation of non-state actors in global governance processes. This specific application has been chosen for mainly three reasons:

- Much of the hopes for a benign transformative impact of ICT are pinned on this type of political grass-roots empowerment;

- The precarious temptation to infer structural social transformations from specific technological properties appears to be particularly strong in this area; and,

- The transformation of global governance regimes from state-centered systems towards greater complexity and involvement by non-state actors has received much attention and developed into a preeminent research area for International Relations (IR) research.

Given the scope of this paper and the speculative nature of the topic, it will only be able to offer a number of anecdotal observations and grainy hypothesis, that, while diverging somewhat from the mainstream thinking on the digital divide, are neither less substantiated nor less plausible than the conventional lines of reasoning. It is hoped that these think-bites will shed some light on a rarely discussed political dimension of the digital divide. The debate may contribute to a more integrative and sustained policy agenda that goes beyond mere resource mobilization if attention is drawn to some of the political and economic co-ordinates that impact the role of nonstate actors in harnessing ICT for participation in global governance regimes.

\section{Civil Society, Global Governance and the Internet}

The conjuncture of two major trends has vastly expanded the role of non-state actors in global decision-making processes. First, the proliferation of economic, social, and political transborder interdependencies has significantly diminished the autonomy of 
the nation state and made international co-operation a prerequisite for effective policy-making in many areas. ${ }^{9}$ This has given rise to a proliferation of international fora and negotiations which, although primarily state centered, also serve as focal points and lobby/networking infrastructure for non-state actors. ${ }^{10}$

Second, civil society organizations have gained significant weight in the political process for various reasons including historical ones (their acclaimed role in toppling communist regimes across East and Central Europe in the 1980s ${ }^{11}$ ), functional ones (growing appreciation as partners for implementing policies, information providers and generators of social cohesion and trust ${ }^{12}$ ) or normative ones (shifting conception of political legitimacy, which accords a greater role to alternative forms of participation, devolved collective decision making and self-governance beyond the conventional political process). ${ }^{13}$ In other words, both global decision-making and the involvement of non-state actors are on the rise and inspire academic scholarship across various disciplines. ${ }^{14}$

Both growing interdependence and the ascent of non-state actors are interlinked with the emergence of a global information and communication infrastructure. Coordinating economic activities on a global scale is predicated upon fast and cheap global communication as is of course the globalization of the media and the working of international political regimes itself. ${ }^{15}$ By the same token, plummeting costs of computing power, the emergence of the Internet as global information space and medium for one-to-many modes of communication have lowered the organization costs for civil society organizations and boosted their mobilizing and lobbying capacities. It is this grass-roots democratization of communication and information flows, which holds the promise to free civil society from the straightjacket of overzealous state censorship or corporately controlled mass media and equip them to successfully enter the fray of negotiations in international governance regimes. ${ }^{16}$

Despite being mainly relegated to consultative status, their impact should not be underestimated in a world that is more and more understood to function along lines of "softpower."17 The capacities to frame issues, to shape cognitive templates and agendas, to focus public attention, mobilize support and forge issue coalitions are increasingly recognized as strategic resources in a context of complex global interdependencies, where reliance on hegemonic economic or military prowess alone can be rather costly or ineffective. Information and the capacity to access, process and disseminate it with strategic timing lies at the heart of this jostling for the limelight and legitimacy on the international stage. ${ }^{18}$ And the Internet has significantly leveraged these capacities for civil society organizations.

At least this is how one strand of theorizing goes - and parts of it appear to hold up well to the emerging evidence: Analyses of transnational advocacy networks for 
human rights, environment and gender issues find a significant impact of these coalitions on shaping international norms, regime structures and policy-making in the respective issue areas. ${ }^{19}$ These findings are corroborated by a growing number of case studies on international regimes, including the spectacular civil society success stories with regard to banning landmines ${ }^{20}$ and stopping the Multilateral Investment Agreement. ${ }^{21}$ The direct causal impact of a diverse and pervasive medium like the Internet on all these activities is almost impossible to establish. Nevertheless all studies seem to agree that the Internet fulfils a significant supportive, if not necessary function. ${ }^{22}$

\section{The Digital Divide and International Governance}

What does this mean for developing countries and the global digital divide? For a start, it appears quite straightforward to argue that the lack of access to these novel communication and information technologies diminishes the possibilities to get heard and participate relative to stakeholders that have the resources to quickly adopt these novel technologies. One would argue that, while civil society in rich industrialized countries is able to catch-up somewhat with governments and transnational business in terms of information competence, civil society in developing countries is falling even further behind.

At closer inspection this argument needs some qualifications, since it appears to lean precariously towards an overly simplistic conception of communication and information flows. In particular it fails to consider the multiplicity of technical tools and social arrangements that process and move information, the interlocked nature of these arrangements and hence the various organizational possibilities for consolidating and articulating political claims. True, from an idealist democratic point of view the target of one voice-one computer might maximize democratic participation in electronic communication networks for global governance. Needless to say that this is not feasible. Nor would it be a sufficient condition for a substantive democratic process, given other inequities in information access, processing capacities, time resources etc.

From a strategic perspective it appears more desirable to focus on the collective arrangements that exist to pick up the voices on the ground, bundle them and feed them into the political process. ${ }^{23}$ This perspective directs attention to the many intermediaries that make up this communication conduit: grass-roots organizations on the village or community level that are linked with domestic advocacy groups, which in turn network with international NGOs. The mechanisms that sustain information flows across these interwoven networks are manifold: face-to-face communication in personalized interaction within social and professional networks, preparation and 
distribution of written material, community radio etc. In a very simplified way the corresponding information chain might look like this:

\section{Community $\leftrightarrow$ Grass-roots Organization $\leftrightarrow$ Domestic Aggregation $\leftrightarrow$ International Advocacy Platform $\leftrightarrow$ International Governance Regime}

Of course this stylized conception diverges from reality in many important respects:

Relationships are not necessarily cascading or hierarchical, the shift from local to domestic to international does rarely correspond with organizational boundaries. The chart might rather be read as the idealized procedural sequence that translates individual needs into concrete political claims to be fed into a specific international bargaining process by civil society. It shall be argued that the cluster of domestic aggregation is the pivotal sector to look at, when assessing the impact of the digital divide on voice in global governance. It is the networking of a myriad of grass-roots initiative, the bundling of voices into demands and claims and the process of feeding them into international advocacy networks, where a potential digital divide can wreak most havoc.

For the "community $\leftrightarrow$ grass-roots organization"-link, conventional modes of communication and information engrained into a fine mesh of personalized relations, social and professional networks, relative frequent contact etc. offer viable alternatives to ICT based information exchange. ${ }^{24}$ However, these means cannot compete with the times-space compression achieved by the Internet. Information flows from remote insular communities can be infrequent; transmission might be slow relative to the chronopolitics of the global. ${ }^{25}$ Nevertheless, complex emergencies that require immediate action aside, the absence of sophisticated Internet based technologies does not seem to stand much in the way of maintaining information flows between the community and articulating needs from the grass-roots level upwards. A digital divide might exist, but this is not automatically a broken link in communication and information flows.

Likewise, the digital divide in its common conception as ICT disparities between developing and developed countries does not appear to play much of a role in the “international advocacy network $\leftrightarrow$ international regime”- link. The argument here goes the other way round: it is not the availability of alternative established modes of communication that render the digital divide less important, it is rather that there is no significant disparities in access to ICT in the first place, when it comes to international civil society advocacy networks vis-à-vis other stakeholders such as international business etc. Building on falling ICT prices and aided by the emergence 
of numerous free services for E-mail, website hosting, discussion groups, the Internet has become a pervasive and ubiquitous tool for international civil society networks.

It is beyond the scope of the paper to elaborate on the available cyber repertoire, which ranges from information networking based on topic-oriented mailing lists or mobilizing via E-mail alert to building an alternative information platform on the web. The digital infrastructure to support international advocacy networks is well developed. Mailing and discussion lists exist for every conceivable topic or can on demand be set up through free, easy-to-use online services. International advocacy networks have established vast websites, compiling extensive amounts of information, providing interactive services and up-to-date news coverage.

Most importantly umbrella aggregators such as OneWorld or Eldis have evolved to provide a platform for content and web presentations by a myriad of smaller organizations. ${ }^{26}$ Taken together free Internet services and the ICT resources of international advocacy networks provide a solid installed base of ICT infrastructure that can be harnessed by domestic advocacy groups in developing countries.

\section{The Pivotal Role of Domestic Aggregation and Domestic Policies}

Alternative means for information transmission on the grass roots level, on the one hand, and the availability to borrow ICT infrastructures for the last linkage between international networks and international regime, on the other hand, point to the importance of the information and communication capacities at the layer of domestic aggregation of voices. It is here, where the digital divide might possibly matter most.

Solid empirical evidence on the diffusion of ICT within this sector is very difficult to come by. Two general observations, which make the digital divide appear in a different light, should be borne in mind however:

- Civil society organizations in many countries around the world are overproportionally middle-class phenomena, suggesting an above average skill and income level that put the disparaging overall inequities in Internet diffusion somewhat in perspective. This is not to say that the endowment with basic ICT is sufficient. Many organizations are woefully starved of resources. However, the gap appears to be smaller than the aggregate country-level number crunching with regard to ICT might suggest;

- More importantly, accepting the assumption that the crucial link is the domestic aggregation of voice and the embeddedness of the aggregating agents into international advocacy networks redirects the analysis of representation in global governance to the enabling and disabling factors for domestic aggregation. 
In other words, the conditions for a thick and vital civil society are a great deal more important for participation in global governance than the incidence of digital inequities. Scholars from various disciplines have come to the quite consensual insight that the existence of a thriving civil society is very much a function of domestic factors. Explanatory power is accorded to a host of structural variables such as ethnic and socioeconomic configurations, historical trajectories of nation-building and, most importantly for our analysis, the characteristics of the political regime and the political space as shaped by the incumbent government. ${ }^{27}$

Domestic laws, policies and political practices pertaining to freedom of organization and expression provide the framework for civil society activities. It is quite straightforward that outright oppression of civil society organizations is severely constraining the public space for political claim making. However, the thickening of civil society and their ability to amplify grass-roots voices and feed them into international networks is also highly contingent on a variety of more subtle enabling and disabling factors, such as media policies, freedom of information practices within the domestic bureaucracy, co-operative or confrontational policy styles etc.

What are the implications of these points for the debate on the digital divide? The paramount importance of domestic factors for the functioning of civil society highlights the domestic political responsibility for a civil society voice in global decision-making. Domestic policy makers in repressive regimes, who routinely join in the choir of complaints about asymmetric representation of cultures and languages on the Internet, can effectively strengthen the digital engagement of their communities by removing roadblocks to civil society activity. Very often, it is domestic divides in political participation rather than inequities in the global distribution of the Internet that shape the strength of the voices of domestic civil society in global governance processes. Putting useful administrative and political information online, such as legal texts, draft regulations, proceedings of meetings and hearings, planning material or environmental indicators, creates a strong pull-effect for online political engagement. Removing legal barriers to the formation of civil society organizations, promoting a political climate of openness, deliberation and freedom of speech and involving civil society more closely in the design and implementation of public policies provide powerful stimulants for developing an organizational infrastructure for voice, engagement and advocacy. These enabling provisions will also enhance participation and visibility of domestic actors in global governance processes.

\section{From Digital Divide to Digital Opportunity?}

So far it has been argued that the digital inequities as referred to by the concept of the digital divide do not in themselves significantly alter the existing asymmetric patterns of representation in global governance processes and that it is the domestic conditions 
for civil society activity that are important in the first place. While this establishes the primary responsibility of domestic policy-making, it also raises the question to what extent a closing of the digital divide could compensate for an adverse domestic political environment and other constraints. Three interrelated effects, each discussed in more depth below, might be possible. Enhanced endowment with ICT could:

- Help to outmaneuver domestic political control mechanisms on the flow of information;

- Stimulate political engagement and civil society activity in general; and,

- Substitute for a possible weak link to international advocacy channels and disintermediate the information flows to the public and other participants in the governance regime.

\section{ICT to Outwit Domestic Government Control on Information Flows?}

Popular reviews of Internet technologies brim with enthusiasm over the alleged grassroots empowerment the Internet offers. State control over information flows, the story goes, is rendered ineffective. "The Net routes around censorship" is a popular comment that acknowledges technical properties as inherently liberating and defying central control. ${ }^{28}$

However, these assumptions require some qualifications: First, the Internet, at least in its current form, is far from a non-hierarchical network. Core functions such as the Internet Domain Name System, which enables navigating in cyberspace, or the clientserver architecture, with end users (client) gaining access to the Internet and sending all data through a specific gateway node (server) are essentially hierarchical or at least perform gatekeeping functions, thereby multiplying vulnerable entry points for monitoring of data traffic, surveillance of individual online behavior or interruption of connectivity to end users/websites. ${ }^{29}$

True, technologies exist that allow one to remain anonymous, prevent interception of E-mail communication or route around blocked websites. Most of the time however these technologies are confined to a technology-savvy cyber elite. ${ }^{30}$ Publicly stated commitment to monitoring of the Internet coupled with often draconian sanctions and showcase seizures, provide a sufficient level of credible deterrence. The average Internet user does not command the technical competence and confidence to safeguard her information privacy and anonymity in what is often perceived as a technology race between an IT-savvy regime and the development of subversive online tools. Censorship cannot be watertight, but raising the barrier for the bulk of Internet users is possible and relatively effective. ${ }^{31}$ 


\section{ICT as Political Stimulant?}

It is very doubtful whether the Internet can act as an independent stimulant for political engagement. A growing body of literature suggests that the Internet can act as an amplifier or inhibitor of existing predispositions but it is unlikely to create them. It might lower the transaction and organization costs for civil society and thus deliver a formidable boost to the mobilization of existing networks across vast physical spaces, but it neither appears to be a sufficient condition for the creation of these networks, nor does it automatically install a deliberative democratic culture among its users. $^{32}$

But what about the impact of access to alternative information? Does this pull more people into civil society activism? True, the Internet can enhance the flow and distribution of alternative information, provided the state does not follow a heavyhanded regulatory approach. However, it should rather be argued that this boils down to an electronic supplement of existing political rumor mills and a gateway to alternative views for people who have been actively engaged with these issues before. The new Internet user, who is disinterested in political affairs, will rather explore the playboy- and mtv.coms than the bbc- or amnesty.orgs of the new information worlds.

Furthermore, the transformative impact of access to critical international information is often exaggerated. External information can often not be readily fed into the domestic discourse. Building on understandable post-colonial nationalist sentiments, political regimes have over time instituted a number of informal rhetoric defenses that have become firmly entrenched in the domestic political discourse. Information from external sources is branded as neo-colonial, infringing on state sovereignty, driven by vested interest, ignorant and disrespectful of a cultural or political otherness. While much of this rhetoric is revealed by informed civil society opinion leaders as such, it has made its mark on the domestic popular debates, instilling a great deal of suspicion about "Western" criticism, forcing even the domestic messengers to tread very carefully so as not to convey the image of a henchman of foreign powers.

In the long-term a genuine stimulant for civil society activism might arise from a very unlikely place: the very popular chat rooms and free discussion lists. While these fora are rarely explicitly political they facilitate, doubtlessly aided by the anonymity they grant to participants, informal chat and uninhibited exchange about what are often very personal issues. These acts of finding out about like-minded people with similar problems, demands and interests can support a learning process, in which problems that were previously experienced as singular and particular to one's private lifeworld become understood as wide-spread and eventually systemic deficiencies of a specific social, economic configuration. ${ }^{33}$ Informal apolitical anonymous chat might in the 
long-run build up grass-roots political ferment. This however appears to be a rather distant and long-term transformative option.

\section{ICT to Amplify Voice in International Arena?}

To what extent can increased Internet use within civil society of developing countries substitute for insufficient inclusion in international advocacy networks? This is a very interesting and important question. It relates to a concern that is often raised by critics of a strong role for civil society in global governance processes. According to this view, the structures of international advocacy have been established and continue to be operated by a number of undemocratic, unaccountable Western NGOs, which only reflect the narrow band of "luxury" values of a small elitist Western clientele. For the sake of the analysis here, the argument, which is susceptible to criticism from various angles, will be taken at face value.

Let us assume civil society organizations in developing countries want to press issues that do not befit the agendas of international advocacy networks. What are the chances to harness the Internet for creating an alternative advocacy platform and take the cause directly to the public, the media and the international policy-making forum? At first sight, it looks like the Internet provides ideal tools to cut out intermediaries of any kind: After all, setting up a website is by now relatively easy and inexpensive. As mentioned before, various free services are available online, ranging from web-based E-mail accounts and mailing list tools to website building toolkits and free hosting services. Also, many established discussion fora are un-moderated making it easy to post statements, which do not undergo editorial control. Moreover, inexpensive oneto-many communication afforded by E-mail makes it possible to distribute a statement to hundreds or even thousands of media outlets and policy makers in a relatively effortless manner.

While these scenarios suggest opportunities for a radically democratized articulation in the digital arena, two fundamental problems stand in the way of genuine disintermediation:

- Information glut - attention poverty: The amount of information stored on and flowing through the Internet has reached truly monumental dimensions. ${ }^{34}$ This information glut meets a relatively constant capacity and willingness to gather and process information on the part of the user. If the bottleneck was ever availability of information, it has now shifted to attention. ${ }^{35}$

- Reputation problem: The democratization of online publishing has lead to an impressive but equally bewildering plurality of news sources, voices, and eyewitness reports. 
Conventional systems of quality assurance and verification as cultivated and institutionalized in the editorial process and brand journalism are being bypassed. The liberation from editorial control and corporate journalism comes with a loss of reputation and trust. ${ }^{36}$ This is not to say that the signifiers for quality information are forever linked to specific gatekeepers. But they are scarce, need to be earned hard and underscore the persisting importance of intermediaries. Taken together, information glut, attention poverty and the reputation imperative create a very difficult environment for gaining voice in the online environment as indicated by a number of worrisome trends:

\section{The Fading Novelty of E-mail}

In the early days of the Internet, E-mail appeared to be a fabulous tool to bypass hierarchies of all kinds and convey information straight to the desired contact. Highlevel representatives of government, bureaucracies or media would make their E-mail addresses available and invite direct contact in order to showcase their openness and progressiveness. With the popularity of E-mail rising rapidly and daily E-mail volumes for important decision makers in the hundreds, these open-access policies have become ever less feasible. It is probably fair to say that by now the handling of unsolicited E-mail has been institutionalized along the conventional lines of office routines and information consolidation through analysts and administrative staff. ${ }^{37}$

\section{The Enduring Primacy of the Issue-attention Cycle}

Much hope of an Internet led democratization has been fueled by some early successes of grass-root organization to harness the Internet for drawing public attention to their cause. The Zapatista uprising in Chiapas provides probably the most prominent example. ${ }^{38}$ However, it is more than doubtful whether a similar campaign today might be able to mimic this early success story. The Zapatista uprising enjoyed a considerable first-mover advantage in the use of the new media. Rather than facing overcrowded "infotainment" spaces it found a receptive early adopter audience, excited to explore the novelty of the Internet and its applications in "meat space" struggles. Moreover, the use of highly sophisticated technology by a jungle-based, people's movement provided an unrivalled icon for the hopes and dreams associated with the magic bullet Internet, a notion that fared well at that time. The "jungle-high tech" contrast was found highly newsworthy in itself. By now all this enthusiasm has faded somewhat. In the times of cyber sobriety and ubiquitous cyber activism the rules of the news and issue-attention cycle can be expected to bite again. ${ }^{39}$ All-out cyber mobilization in combination with significant offline activities, such as the recent Seattle activities, might manage to refocus attention on cyber campaigns for a limited period of time. The main focus at the writing of this article however has 
moved to alleged cyber wars and virus attacks. Internet direct actions proliferate. They become increasingly routine events from the perspective of news coverage and no longer manage to garner much attention beyond the established circles of activism and engagement

\section{The Staying Power of Brand Names, Gatekeepers and Resource Rich Content Providers}

Established information providers such as the major newswires and media conglomerates have in many cases successfully leveraged their scale advantages in news production and syndication into the online world. ${ }^{40}$ The explosion of online information stands in stark contrast to the extraordinary concentration of web traffic on a small number of portal sites. ${ }^{41}$ While a few new online information portals have gained prominence, they rarely build up extensive capacities for in-house content production or journalistic research, but mostly rely on news feeds from a limited number of established newswires. Likewise the proliferation of e-commerce sites has turned portal websites that aggregate large user groups into coveted online billboards. Online advertising prices have skyrocketed, making it nearly impossible for civil society content to have a link to their sites placed prominently on one of the big online portals.

\section{The Non-Transparent Organizing of Meta-Information Online}

No authoritative meta-directory structures information in cyberspace. Users navigate with the help of domain names and private search engines, which only manage to catalogue a portion of the Internet. Keyword searches operate with non-transparent index and search techniques that effectively put the visibility of websites at the discretion of search engines. Some search operators have embarked on a dubious practice to sell off premium spots in their listings rather than rely on an automated search heuristic. Often these commercial placings are poorly marked as such. The user is presented with a mélange of search hits and advertising, while expecting an impartial execution of her search. ${ }^{42}$

\section{Walled Gardens}

New business models for the Internet are geared towards the creation of alliances between content and conduit providers. Internet access and service providers increasingly team up with large media conglomerates in the hope of exploiting synergies through cross-promotion and customer sharing. The recent Time WarnerAOL merger is a harbinger for the type of marriages between content and conduit to come. Through various design mechanisms Internet users are lured to spend as much online time as possible within the proprietary content space instead of clicking off 
into the wider Internet. These so-called walled gardens are not a distant scenario but have already become reality. As news reports revealed AOL has imposed a number of contractual obligations on Disney, a major content provider to the AOL portal site. In order to minimize the number of people leaving the AOL compound, AOL demanded that Disney keeps the number of external hyperlinks from its pages limited and included the right to financial compensation in case more than $25 \%$ of people would follow external links from the Disney site. ${ }^{43}$ In the near future content discrimination on the Internet will go far beyond web design issues. Current mobile Internet technologies (WAP) and some forms of high speed Internet diverge from the open access principle that has laid the foundations for content plurality on the Internet in the first place. WAP gateways for example only give users access to content providers that have signed up with their mobile access operator. Similarly, owners of high-speed infrastructure are not mandated to provide open access to their networks for all Internet service providers, thereby adding another layer of gatekeeping. ${ }^{44}$

\section{The Political Dimension of the Digital Divide}

As this brief enumeration indicates, the list of barriers to stand-alone online representation is comprehensive. The hurdles for civil society organizations from developing countries to independently gain significant visibility and attention for an underrepresented standpoint are formidable. The chances to provide a widely recognized alternative framing of issues that makes its way onto the negotiation table of global governance regimes are dim.

Again the plurality of visible opinions hinges on old and new gatekeepers and is severely narrowed by the economies of news production and the well-known psychology of the issue-attention dynamics. To put it very bluntly: the fact that websites can be set up easily does by itself as much or little to increase media presence as the acquisition of a phone.

It is interesting to note, that, while we embarked on the argument from the perspective of underrepresented civil society in developing countries, the very same challenges also apply to the voice of civil society in general. The opportunities afforded by new communication and information technologies with regard to a voice for civil society in global governance is not so much a question of ICT resources, but of sensible media and communication policies. The Internet is not a substitute for committed anti-trust policies that curb concentration, for far-sighted communication policies that guarantee open access to the conduits, for media regulations that mandate a transparent difference between commercial promotion and impartial information. 
These are just a few items for a media agenda, which in principle is not new, but has become longer and acquired a new taste of urgency through the advent of the Internet. ${ }^{45}$ The well-known structural imbalances that have long distorted the distribution of media might around the world are not suspended but continue to mould information and communication flows in the Internet age.

Moreover, the efficacy with which civil society can use ICT to contribute to global governance processes and enhance their democratic legitimacy hinges on a conducive procedural framework underpinning international regimes themselves. A narrow fixation on electoral accountability is not helpful in this context. As Nye and Keohane have noted, the opening of a public space for deliberation, which interfaces with the actual decision making process in the broadest way possible can significantly enhance input legitimacy. On a procedural level this includes stepping up substantive consultative processes with civil society, the opportunity to file amicus briefs, rigorous transparency not only for policy outputs, but also for the negotiating processes itself. ${ }^{46}$ ICT can greatly support these efforts through a variety of means such as online consultations, online posting of proceedings, automated notification of feedback deadlines etc. ICT however cannot substitute for reluctance on the part of governments and international organizations to increase transparency and strengthen accountability.

Summing up, policy-makers that are serious about maximizing the opportunities from ICT towards a new culture of democratic legitimacy in global decision-making process should be aware of their responsibilities:

- Domestic ones, in order to enable a thriving civil society;

- International ones, in order to increase the plurality and visibility in the global information space; and,

- Global regime ones for the case of global governance reform towards greater public deliberation, transparency and accountability.

Taken together this is the critical political dimension of the digital divide when it comes to delivering on the democratic promise of ICT in global governance regimes.

Similar points for the overriding importance of policies and regulatory frameworks could be made for other applications for ICT. Economic participation in globalized Business-to-Business marketplaces, for example, faces formidable policy challenges in the form of anti-trust issues, access to intellectual property, deployed software standards in payments systems, privacy regulations etc.

As long as the developmental rhetoric about the digital divide confines itself mainly to questions of ICT resources and market liberalization and shirks these more uncomfortable issues, it rather reeks of a project to ensure the continued growth of 
ICT exports than a sincere effort to bridge divides and help developing countries realize the potential of ICTs. Or to end on a more upbeat note:

The digital divide and the question of how to channel the novel information technologies towards human development could be a welcome opportunity to revisit some more fundamental structural asymmetries that are at the root of not only the digital but many other divides and hence to reinvigorate a policy debate that moves beyond simplistic ideas of open markets and limited resource transfers to sufficient guarantors to reap the benefits of technological advances on an equitable basis.

DISCLAIMER: The views expressed in this article are views of the author only and should by no means be associated with UNDP.

\section{Notes:}

1 Tim Jordan, "Measuring the Internet: Host Counts Versus Business Plans," Information, Communication \& Society 4, 1 (2001): 34-53.

2

3

Ibid.

Ibid.

Telegeography, Hubs and Spokes: A Telegeography Internet Reader (Washington DC: Telegeography, 2000).

5 International Telecommunication Union, Challenges to the Network: Internet for Development (Geneva: International Telecommunication Union, 1999).

Jordan, "Measuring the Internet," provides an interesting breakdown of Internet hosts according to GDP per capita and human development level as measured by the UNDP Human Development Index. Unsurprisingly skewed host distribution mirrors human development and income distributions and the host shares for each group have not changed significantly between 1998 and 2000.

7 Emblematic for this strand of thinking is the astonishing statement by Bill Gates: "The world's poorest 2 billion people desperately need healthcare right now, not laptops," (quoted in: New York Times, November 3, 2000, A1), which has been widely picked up upon by the media and also entered professional debates about development policy.

See for example the widely cited e-Readiness initiative (http://www.readinessguide.org/), which provides a comprehensive but very abstract checklist for assessing infrastructure and institutional shortcomings relative to an ideal of a networked society and economy. In doing so, the guide helps draw up a sweeping agenda for resource mobilization and regulatory policy reform for the sake of bridging the divide. It barely considers 
socioeconomic specificities or concrete ICT applications and thus fails to identify a more integrative policy framework linked to goals of human development.

Robert Keohane and Joseph Nye, Power and Interdependence (Boston: Little Brown, 1977).

10 Sidney Tarrow, Beyond Globalization: Why Creating Transnational Social Movements is so Hard and When is it Most Likely to Happen (New York: Cornell University, 1999). Available @ http://antenna.nl/ waterman/Pages/general/tarrow.htm, accessed May 30, 2001.

11 John Keane, Civil Society: Old Images, New Visions (Polity Press: Cambridge, 1998), 19-23.

12 Robert Putnam, Making Democracy Work: Civic Traditions in Modern Italy (Princeton, NJ: Princeton University Press, 1993).

13 Claus Offe, "Challenging the Boundaries of Institutional Politics: Social Movements Since the 1960s," in Changing Boundaries of the Political, ed. Charles Maier (Cambridge: Cambridge University Press, 1987), 63-105.

The proliferation of new concepts related to these phenomena is impressive. Concepts range from the seminal descriptive template of "complex interdependence" (Keohane and Nye, 1977) to bolder categories such as "world polity" (John Boli and John Thomas, eds., Constructing World Culture: International Nonvgovernmental Organizations Since 1875 (Stanford: University Press, 1999)) and, with particular reference to the role of civil society , "cosmopolitan model of democracy" (David Held, "From City-States to A Cosmopolitan Order?" in Prospects for Democracy, ed. David Held (Cambridge: Polity Press), 13-52) or transnational social movements (Donatella Della Porta, et al., Transnational Social Movements (London: MacMillen, 1999)).

Manuel Castells, The Rise of the Network Society (Oxford: Blackwell, 1996).

For an enumeration of tools provided by the Internet for influencing foreign policy, see Dorothy Denning, "Activism, Hacktivism, and Cyberterrorism: The Internet as a Tool for Influencing Foreign Policy” (1999) [unpublished paper online at: http://www.nautilus.org/info-policy/workshop/papers/denning.html, accessed May 28, 2001].

17 Robert Keohane and Joseph Nye, "Power and Interdependence in the Information Age," Foreign Affairs 77, 5 (September/October 1998): 88-93.

18 Contributions from various theoretical and methodological backgrounds appear to converge around a recognition of the importance of soft power. These include cognitive approaches in international relations (for an overview see Stephan Haggard and Beth Simmons, "Theories of International Regimes," International Organization 41, 3 (1987): 491-517); mobilization analysis in the field of contentious politics (see Tilly, From Mobilization to Revolution (Reading, MA: Addison-Wesley, 1978); Margaret Keck and Kathryn Sikkink, Activists Beyond Borders (Ithaca: Cornell University Press, 1998) and as strongest variant, communication research in the tradition of media imperialism (Herbert Schiller, Communication and Cultural Domination (White Plains, N.Y.: International Arts and Sciences Press, 1976). On the applied level of policy strategizing the importance of soft power is reflected in strategies such as issue management (Phil Agre, "The Dynamics of Policy in a Networked World" (1999) [unpublished paper online at: http://www.nautilus.org/info-policy/workshop/papers/agre.html, accessed at 25 
May 2001]) or "Noopolitik" (John Arquilla and David Ronfeldt, The Emergence of Noopolitik: Toward an American Information Strategy, MR-1033-OSD (Santa Monica, CA: RAND, 1999)).

Keck and Sikkink, Activists Beyond Borders.

Richard Price, "Reversing the Gun Sights: Transnational Civil Society Targets Land Mines," International Organization 52, 3 (1998): 613-644.

Peter Smith and Elizabeth Smythe, "Globalization, Citizenship, and Technology: The MAI Meets the Internet" (paper presented at International Studies Association Annual Convention, Los Angeles, March 14-18, 2000).

Keck and Sikkink see one strategic advantage of transnational networks in their ability to move information quickly and effectively between participants, a task greatly aided by the Internet (Keck and Sikkink, 1998) and confirmed by detailed studies on the role of the Internet in toppling the MAI (Smith and Smythe, 2000), advancing the ban of landmines (Ken Rutherford, "The Landmine Ban and NGOs: The Role of Communications Technologies" [unpublished paper available at: http://www.nautilus.org/info-policy/workshop/papers/rutherford.html, accessed at 25 May, 2001]) and anecdotal evidence from various other campaigns (Denning, 1999).

Keck and Sikkink elaborate both on the mutual benefits of this process. While grassroots voices and personal stories gain amplification, albeit often in a morphed and decontextualized form, international advocacy networks gain valuable legitimizing testimony to back up their claims (Keck and Sikkink, Activists Beyond Borders, 18-19).

The literature on development communication provides an interesting strategic perspective on the multiple channels and arrangements that support information flows within communities in developing countries. For an overview see Adam Burke, Communications and Development: A Practical Guide (London: Department for International Development, 1999). Organizational studies emphasize the pivotal importance of communities of practice as arrangements to compare notes, exchange information, convey tacit knowledge etc. These communities of practice are not bound to a specific formal organizational structure or a specific communication medium, but thrive through various social arrangements (Etienne Wenger, Communities of Practice: Learning, Meaning, and Identity (Cambridge: University Press, 1998)).

The phrase "chronopolitics" has been coined by Paul Virilio to describe the acceleration of the political process and the increasing importance of time, timing, response time etc. as strategic resources within it. See Paul Virilio, Speed and Politics: An Essay on Dromology (New York: Columbia University, 1986).

See www.oneworld.org, which provides a metastructure for development related content from a myriad of partner organizations from around the world, and www.eldis.org, which structures development related research and links to think tanks.

Scholars of social movements and contentious politics stress this point. They have developed the concept of political opportunity structure, which encompasses the responsiveness to claim-making of the formal political process, as well as concrete policies and strategies adopted by the state that impinge on working of civil society groups (Sidney Tarrow, "States and Opportunities: The Political Structuring of Social Movements," in Comparative Perspectives on Social Movements, ed. Doug Mc Adam, et al. (Cambridge: Cambridge University Press, 1996)). With regard to transnational 
networks, Tarrow emphasizes the persistent grounding of movement agents and repertoire in domestic political configurations and domestic social networks.

See for example Wade Rowland, The Spirit of the Web: The Age of Information from Telegraph to the Internet (Toronto: Somerville House, 1997).

For an excellent introduction to architecture and governance of the Domain Name System see Craig McTaggart, Governance of the Internet's Infrastructure: Network Policy for the Global Public Network, Dissertation (LLM, University of Toronto, 1999). The control implications of the client-server architecture are highlighted in the current discussion on novel peer-to-peer software tools that promise to threaten these hierarchical control mechanisms (for a very accessible introduction see: "Peer to peer pressure," Economist, November 2, 2000). Likewise, the current discussion on law enforcement on the Internet in many countries underscores the repertoire of available tools to monitor Internet use (see for example http://www.computerworld.com/ resources/carnivore/ for a resource collection on the US "Carnivore" monitoring system), whereas the debate on information warfare and critical infrastructure protection illustrates the various possibilities for disrupting connectivity (Dorothy Denning, "Cyberterrorism," testimony before the Special Oversight Panel on Terrorism, Committee on Armed Services, U.S. House of Representatives, May 23, 2000, available @ http://www.cs.georgetown.edu/ denning/infosec/cyberterror.html, accessed May 24, 2001).

30 One should not make the mistake of presupposing a large overlap between civil society activism and the IT-savvy hacker scene. The public image of a libertarian spirit among Internet activists in industrialized countries suggests a certain affinity with values that are commonly associated with some clusters in civil society. It is questionable to what extent this affinity translates into direct involvement with more organized civil society activism. This might be even more true for developing countries where hacker communities developed in different social contexts and might espouse different shared values and principled believes.

These arguments are based on a series of interviews the author conducted with civil society organizations in Southeast Asia from 1999 till 2001.

See Keck and Sikkink, 1998, for the interpersonal prerequisites for electronic advocacy networks. Norris undertakes a cross-national survey in her forthcoming book and arrives at the conclusion that "those who take advantage of the opportunities for electronic civic engagement tend to be activists who would otherwise participate via conventional channels." (Pippa Norris, Civic Engagement, Information Poverty and the Internet Worldwide (New York: Cambridge University Press, forthcoming Autumn 2001), Chapter 1, 10). Denning, Activism, Hacktivism, and Cyberterrorism, notes the defamatory and anti-discursive nature of many unmoderated usenet discussion groups.

Following Ross, McAdam et al. describe this tendency to mistake systemic deficiencies for individual flaws as the "fundamental error of attribution" (Doug McAdam, et al. "Introduction," in Comparative Perspectives on Social Movements, ed. Doug McAdam, et al. (New York: Cambridge University Press, 1996)).

See Lyman and Varian for an ambitious attempt to gauge the overall expansion of available information, which puts the annual growth rate of computer-stored information at 100 (Peter Lyman and Hal Varian,"How Much Information" [online at: http://www.sims.berkeley.edu/how-much-info on, accessed 30 May 2001]). For estimates 
about growth of traffic on the Internet, which is also estimated to double annually, see K. Coffman and A. Odlyzko, "Internet Growth: Is there a 'Moore's Law' for Data Traffic?" in Handbook of Massive Data Sets, ed. J. Abello, et al. (New York: Kluver, 2001).

For a seminal essay on the information-attention relation, see Herbert Simon, "Designing Organizations for an Information-Rich World," in: Computers, Communications, and the Public Interest, ed. Martin Greenberger (Baltimore: John Hopkins University Press, 1971).

Keohane and Nye, "Power and Interdependence in the Information Age," for example link reputation to their concept of softpower and argue that "asymmetrical credibility is a key source of power."

Denning, Activism, Hacktivism, and Cyberterrorism.

See for example Castells, 1996.

For a seminal study on the issue-attention cycle, see Anthony Downs, "Up and Down with Ecology: This Issue Attention Cycle,” Public Interest 28 (1972): 38-50.

For an overview of the extraordinary concentration in the global media market, see Robert McChesney, "The Political Economy of Global Media," Media and Development 45, 4 (1998): 3-8. For early evidence on the continued market dominance of established information producers in the online world see Matthew Zook, "Old Hierarchies or New Networks of Centrality? The Global Geography of the Internet Content Market," American Behavioral Scientist 44, 10 (2001): [forthcoming].

For recent market figures that confirm strong trends towards concentration, see for example "Four Websites Control Half of Surfing Time," E-Commerce Times (June 4, 2001).

Inclusion and ranking of websites is even more arbitrary for directory services, which are manually referenced and do not rely on automatic indexing. (Helen Nissenbaum and Lucas Introna, "Sustaining the Public Good Vision of the Internet: The Politics of Search Engines," Working Paper \#9, Center for the Arts and Cultural Policy Studies, Princeton University, 1999). For a detailed account on the visibility of non-commercial content on the Internet and the parallels to other media, see Eszter Hargittai, "Standing Before the Portals. Non-Profit Content Online in the Age of Commercial Gatekeepers," paper presented at conference "Shaping the Network Society: The Future of the Public Sphere in Cyberspace (DIAC2000)," May 20-23, 2000, Seattle, U.S.

See "AOL Restrictions Alleged," Washington Post (October 10, 2000), E01.

For WAP and open access see Sohil Parekh, "A Close Look at the Wireless Application Protocol," student paper for course "Autonomy and Information: The Relationship between the Individual and the Government in the Digital Age," John F. Kennedy School of Government, Harvard University, 2000; for cable and open access see, François Bar, et al., "Defending the Internet Revolution in the Broadband Era: When Doing Nothing is Doing Harm," Working Paper 137, Berkeley Roundtable on the International Economy, 2000.

For a major international initiative to tackle information asymmetries see the debate in the $70 \mathrm{~s}$ and $80 \mathrm{~s}$ on a New Information and Communication World Order. For an overview see Ch. Brown-Syed, "The New World Order and the Geopolitics of Information,” 1999 Web Edition, available @ http://valinor.purdy.wayne.edu/ csyed_libres3.html, accessed May 24, 2001. 
46 Robert Keohane and Joseph Nye, Jr., "Between Centralization and Fragmentation: The Club Model of Multilateral Cooperation and Problems of Democratic Legitimacy," Working Paper (Kennedy School of Government, Harvard University, 2001), available @ http://ksgnotes1.harvard.edu/Research/wpaper.nsf/rwp/RWP01-004/\$File/rwp01_004 _nye_rev1.pdf, accessed May 23, 2001.

DIETER ZINNBAUER is a 4th year PhD candidate at the Development Studies Institute, London School of Economics. His research focus is the use of the Internet by civil society organizations in the Asia-Pacific region. Mr. Zinnbauer has also worked as a consultant for various Internet projects for developing countries and is currently editor of the Internet Governance Information Service, which aims at facilitating information exchange on Internet policies among new Internet stakeholders in the Asia-Pacific as part of a regional Internet initiative by the United Nations Development Programme (UNDP). E-mail: d.zinnbauer@1se.ac.uk 